\title{
The Frequency of Xylophagous Fungi in a Plum Plantation from Reghin Area
}

\author{
Valentin BEREKMERI ${ }^{1}$, Raluca MICLEA ${ }^{1}$, Carmen PUIA ${ }^{1 *}$ \\ ${ }^{1}$ University of Agricultural sciences and Veterinary Medicine Cluj Napoca, Romania, \\ * corresponding author: carmen.puia@yahoo.com
}

Bulletin USAMV series Agriculture 72(1)/2015

Print ISSN 1843-5246; Electronic ISSN 1843-5386

DOI 10.15835/buasvmcn-agr: 11146

\begin{abstract}
The main purpose of the study was to observe the frequency of the wood decay fungi in plum plantations and also to identify the species of xylophagous fungi that grow on plum trees. The plum varieties used in the experiment were Anna Spath, De Bistrița, Stanley and Silvia on which the lesions in the trees were counted and the infected lesions were monitored in four plantations. The monitored plantation was affected by two species of wood decaying fungi, identified as Phellinus igniarius and Stereum hirsutum, the frequency of the Stereum hirsutum specie being higher compared with Phelinus igniarius.
\end{abstract}

Keywords: frequency, fungi, plum, xylophagous

\section{INTRODUCTION}

Many xylophagous fungi cause heart rot of living trees, others decay the wood of dead trees and some grow on both alive and dead trees. Most of these decays do not actually interfere with the normal growth of live trees. They can affect tree structure, however and contribute to wind breakage and windthrow (Harmon et al., 2005). Other specialized fungi as Phellinus igniarius may attack the sapwood and cambium of live trees after existing as a heart rot fungus. Each wood decay fungus decomposes wood in one of two ways: by white rot where cellulose and lignin are degraded or by brown rot where cellulose is consumed but lignin is left largely intact. Some wood decay fungi produce mushrooms or other fruiting bodies. Another xylophagous fungus frequent in plum plantations is Stereum hirsutum that causes wood-rotting (Hennon and McClellan, 2003).

\section{Aims and objectives}

The main purpose of the study was to observe the frequency of the wood decay fungi in the plum plantations and also to identify the species that grow on plum trees.

\section{MATERIALS AND METHODS}

The observations were made in four plum plantations around Reghin area (FL, FB, FG and $\mathrm{FH})$. The plum varieties used in the experiment were Anna Spath, De Bistrița, Stanley and Silvia. In order to monitor these xylophagous fungi the lesions in the trees were counted and the infected lesions in the plantations were identified and monitored. The identification of the fungi was made by macroscopically observations of the fruiting bodies.

\section{RESULTS AND DISCUSSIONS}

The observations made in our experiment showed that the plum trees in the monitored plantations were affected by two species of wood decaying fungi, identified as Phellinus igniarius and Stereum hirsutum (Fig. 1). The results showed that in all the plantations monitored and in all the plum varieties the number of lesions was very high (tab. 1) and this is the major cause that facilitates the spreading of the two species. Also we noticed that the frequency of the Stereum hirsutum specie is higher compared with Phelinus 
Tab. 1. The number of lesions presented in the monitored plantations

\begin{tabular}{ccccc}
\hline \multirow{2}{*}{ Variety } & \multicolumn{4}{c}{ Plantation } \\
\cline { 2 - 5 } & FL & FB & FG & FH \\
\hline Anna Spath & - & - & 107 & 23 \\
\hline De Bistrita & 4 & 2 & 7 & 213 \\
\hline Stanley & 46 & 86 & 116 & 367 \\
\hline Silvia & - & - & 65 & - \\
\hline
\end{tabular}

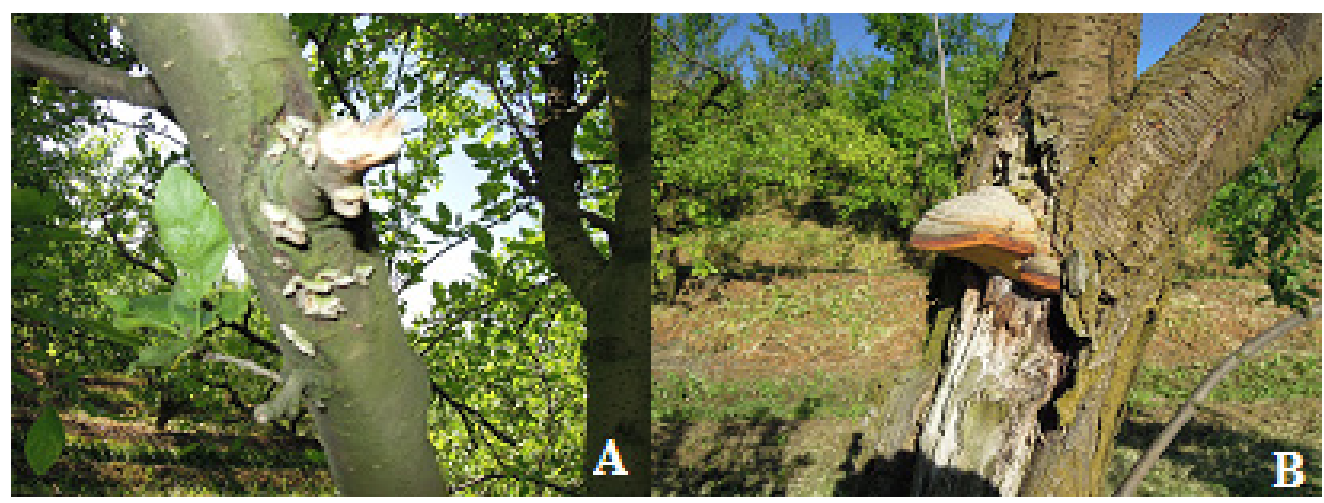

Fig. 1. Lesions infected with Stereum hirsutum (A) and Phellinus igniarius (B)

Tab. 2. The frequency (\%) of infestation with xylophagous fungi

\begin{tabular}{ccccccccc}
\hline & \multicolumn{7}{c}{ Plantation } \\
\cline { 2 - 9 } Variety & \multicolumn{2}{c}{ FL } & \multicolumn{2}{c}{ FB } & \multicolumn{2}{c}{ FG } & \multicolumn{2}{c}{ FH } \\
\cline { 2 - 9 } & Stereum & Phellinus & Stereum & Phellinus & Stereum & Phellinus & Stereum & Phellinus \\
\hline Anna Spath & 0 & 0 & 0 & 0 & 71.42 & 28.57 & 0 & 0 \\
\hline De Bistrita & 0 & 0 & 0 & 100 & 100 & 0 & 85.71 & 14.28 \\
\hline Stanley & 0 & 100 & 0 & 100 & 61.11 & 38.88 & 98.64 & 1.35 \\
\hline Silvia & 0 & 0 & 0 & 0 & 75 & 25 & 0 & 0 \\
\hline
\end{tabular}

igniarius, recording values from $98.64 \%$ in some varieties (Tab. 2).

\section{CONCLUSION}

After the observations made in these plum plantations we can confirm that these wood decaying fungi are very much influenced by the presence of the oxygen in the cambium and sapwood area which is facilitated by great number of lesions produced by the invasive cuttings.

\section{REFERENCES}

1. Harmon M, Fasth B, Yatskov M, Sexton J, Trummer L (2005). The fate of dead spruce on the Kenai Peninsula, a preliminary report, USDA For. Serv. Gen. Tech. Rep., $\mathrm{R}(10) 134: 23$.

2. Hennon PE, McClellan MH (2003). Tree mortality and forest structure in temperate rain forests of Southeast Alaska. Can. J. For. Res. 33:1621-1634. 